\title{
Research and Practice on the Cultivation System of College English Intercultural Communication Ability
}

\author{
Hui Cui \\ Wuhan Donghu University, Hubei, Wuhan, 430060
}

Keywords: college English intercultural; Communicative Competence; Training System; Practice

\begin{abstract}
In this era of economic globalization, economic exchanges between countries have deepened. In this process, English has become the most widely used language, and it has received much attention from all over the world. Colleges and universities have opened application courses in this process. In order to improve students' intercultural communication ability, cultural differences have brought great obstacles to the implementation of this work, and have become an urgent problem to be solved in the current education sector. Based on this, this paper mainly discusses the construction method of the college English intercultural communication ability training system, and then puts forward targeted opinions and reflections.
\end{abstract}

\section{Introduction}

Since the reform and opening up, China's social economy has developed rapidly, and the Chinese have begun to go abroad. In the process of communicating with other people, the metropolis has used English as a universal language. In order to strengthen the English intercultural communication ability of our people, it is necessary to the opening of English courses at the university stage reflects the importance of English teaching. However, at this stage, the college English education system is still not perfect. Therefore, it is necessary to conduct research on the university English intercultural communication ability training system, thus laying a foundation for the development and growth of college students. .

\section{Conceptual Analysis of Intercultural Communication Ability}

At this stage, there is still no expert or scholar who comprehensively expounds the intercultural communication ability and gives a definite definition. Usually, intercultural communication ability is regarded as the ability of intercultural communication, which involves language and culture background. , slang, grammar and pronunciation, etc., some experts and scholars believe that the so-called cross-cultural communication ability refers to the communicative competence that is more suitable in a certain context. However, from the scientific level, due to the differences in regional culture and historical and cultural backgrounds, the meanings embodied in the affected languages will also be different. Therefore, if the essence of language expression is not clearly defined during the communication process, it is easy to cause an error in understanding. In order to ensure the effectiveness of cultural exchanges, the concept of intercultural communication emerges as the times require. The fundamental purpose is to make people's communication more appropriate and effective in the process of intercultural communication [1-3].

\section{The Development of College English Intercultural Communication Ability Training System}

\subsection{Clarify the Goal of College English Intercultural Communication Ability.}

The fundamental purpose of college English teaching is to enable students to use English to communicate and develop their language skills. In this process, students need to have clear English writing skills and English listening and speaking skills as an important part of English communication. In the teacher's teaching work, the grammar knowledge is infiltrated into the students, so that the students can clearly understand the writing style, learn to use the knowledge 
effectively, apply the knowledge learned to the oral expression link, and truly apply what they have learned. However, the cultivation of students' language ability is not limited to the above aspects. If you want to truly achieve the purpose of cross-cultural communication, you must be aware of the differences between cultures, and you should not have an understanding error in the process of communication. Communication cannot continue. Therefore, the cultivation of students' communication skills requires them to solve various problems independently and independently, and to convey valuable information in the process of communication, and ultimately to reflect the role of communication [4-5].

Behavioral ability refers to the effective resolution of conflicts and problems on the basis of clear behavioral norms, especially the problems accompanying intercultural communication. This ability is often called behavioral ability. In the process of intercultural communication, the two sides have different cultural backgrounds. Therefore, it is easy to make actions that the other party cannot understand or dissatisfied in the process. If the situation is serious, they may even touch the opponent's bottom line and involve the other party's taboos. Therefore, the cultivation of intercultural communication skills requires teachers to focus on improving students' behavioral ability, thus laying a solid foundation for students' future growth and development.

Any subject needs to develop students' thinking ability, urge students to think seriously, and solve problems independently and independently. In the process of English teaching, students' thinking ability should also be improved, and students should be guided to consider problems from different angles, so as to establish effective emotions in the dialogue process and respond in a targeted manner. It can be seen that the improvement of thinking ability can be said to be the basic guarantee for ensuring the success of intercultural communication [6-7].

It refers to the cultivation of cultural adaptability and interpersonal relationship. Whether it is the establishment of interpersonal relationship or the infiltration of culture, both parties are required to have good social development ability. Based on the cultural background and social background of both parties, they master each other. The language habits and behavioral differences, etc., change the cultural habits from the self, and cater to the needs of the other party as much as possible. The live cultural communication is more effective.

\subsection{Establishing A High-Quality Teaching Team.}

If you want to improve the cross-cultural communication ability of college students, it is necessary to ensure that the teaching staff has a high comprehensive quality in order to ensure the quality of English teaching to the greatest extent. Teachers first have good cross-cultural communication skills and strong professional qualities. College leaders need to pay attention to the construction of English intercultural communication system, and provide relevant English teachers with opportunities for foreign study, so that teachers can more fully grasp the Western countries. The cultural background, thus clarifying the rules and rules in the process of cross-cultural communication, and correspondingly enhance the intercultural communication ability. For ordinary colleges and universities that lack training conditions, they must adhere to the principle of going out and coming in, hiring experts and scholars with intercultural communication skills and high quality, sharing their work experience, and infiltrating advanced teaching concepts into training. English teachers, thus improving their professional quality, as a whole to ensure the comprehensive ability of the teaching team [8-9].

\subsection{Innovating the Training Methods of Intercultural Communication Competence.}

First, clarify the growth of students and the needs of learning. In the process of English curriculum development, the choice of teaching materials and the arrangement of teaching time will directly affect the quality of college English teaching, and also affect the efficiency of college students' intercultural communication skills. In recent years, many colleges and universities in China have realized the importance of curriculum and its influence on the cultivation of intercultural communication competence of college students. Actively opening different types of college English courses, the view makes new attempts. For example, American culture profiles, English and American newspapers, and practical workplace English. Enriching the curriculum 
system will satisfy the students' learning needs to the greatest extent, and effectively expand their horizons. The content of the course involves listening, speaking, reading, writing and other factors, thus greatly improving students' comprehensive ability and intercultural communication ability. The cultivation has laid a good foundation. The diversification of English courses will enable students to understand British and American cultures more comprehensively and accurately. They can also contact different cultural backgrounds and master the language exchange habits of British and American people, so that the intercultural communication process will be more comfortable and smooth in the future.

Second, reform and update the content of the textbook. In the process of English teaching, the textbook can be described as the core content, which will directly affect the quality of English teaching. In the process of cultivating the intercultural communication ability of universities, we should pay attention to the optimization of the content of teaching materials. At present, most of the college students use the comprehensive reading and writing translation course. In addition, other suitable teaching materials can be applied in a targeted manner to enable students to fully understand the Anglo-American culture and meet the learning and growth needs of students. Promote the teaching materials to be more inspiring and interesting, improve teaching efficiency, and cultivate students' comprehensive ability to effectively improve their cognitive level. In addition, the richness of the content of the textbooks makes it possible to cover a wide range of subjects, taking into account the different cultural levels and cognitive levels of students, and at the same time integrating the content of listening, speaking, reading, writing and translating, laying the foundation for the cultivation of intercultural communication skills. Finally, to make the teaching materials more modern, students find the fun in the learning process, and learn to actively learn English knowledge, mobilize their enthusiasm for learning, generate the driving force of learning, and should be accompanied by electronic texts to guide students. Use information technology to fully understand and master relevant English knowledge to ensure learning efficiency.

Third, reform the classroom teaching methods. If you want to maximize the students' intercultural communication skills, teachers should comprehensively analyze and master the English teaching objectives, and summarize the cultural knowledge involved in the English teaching process. It is worth mentioning that traditional English teaching can not meet the students' needs. Learning needs, therefore, teachers should focus on improving the level of English teaching, and innovative classroom teaching models, for example, can effectively use slang and proverbs, etc., students will improve their enthusiasm for learning and actively understand the slang and proverbs. Connotation will also be used in practice to lay a good foundation for future cross-cultural communication. In addition, teachers should innovate classroom teaching methods from different angles, so that students have a more comprehensive and intuitive understanding of cross-cultural communication related knowledge and improve intercultural communication skills. All in all, teachers must use the contents of the textbook to summarize the differences between the central cultures. From the perspective of Chinese and Western cultural backgrounds, the details are listed to provide students with reference and reference, so that students are highly sensitive to cultural differences and are exposed to exotic customs. In addition, in the teaching work, teachers can also enhance the students' enthusiasm for learning through the way of scenario creation, create a democratic and harmonious teaching atmosphere, and enable students to fully express their own opinions and opinions during the simulation process. For example, in the process of oral expression teaching, teachers can guide students to perform a certain drama of Shakespeare, use the elaboration of lines to feel the inner and emotional state of the characters, master the true meaning of various proverbs, fully understand Western culture, and deeply understand. This kind of teaching method is an organic combination of theory and practice. It truly realizes the theory of practice and gives students a deeper impression. In the process of learning new knowledge in the future, it will inevitably increase interest and generate learning motivation.

Fourth, contact with cultural knowledge to stimulate students' social development ability. In the process of intercultural communication ability training, teachers can use professional cultural knowledge teaching to help students build a sound cultural knowledge framework, thus stimulating 
their social development capabilities. Only the content of the building materials is difficult to make students form a comprehensive and profound seriousness, and it is impossible to improve the intercultural communication ability. Therefore, it is necessary to set up cultural knowledge courses to enable students to master the religions, history and customs of various Western countries, and to understand their values, so as to understand the true meaning of the language and actions used by the other party during the cultural exchanges. Exercise oral expression ability, effectively deal with problems and obstacles in the process of cultural communication.

\section{Conclusion}

In summary, in this era of economic globalization, English has become a universal language. Therefore, the English course at the university level has become an extremely important component of the teaching system, requiring English teachers to develop cross-cultural communication skills in a targeted manner. Clarify students' growth and development needs, elaborate on different language and culture backgrounds, and infiltrate students, thus improving students' cross-cultural communication level and laying a solid foundation for their future growth and development. Finally, I hope that the author's analysis and discussion will bring reference and reference to relevant researchers.

\section{References}

[1] ZHOU Wei. Research and Practice on the Cultivation System of College English Intercultural Communication Ability [J]. Heilongjiang Science, 2015,13(17):108-109.

[2] YU Bin. Research on the Cultivation System of College English Intercultural Communication Ability [J]. Talent, 2014, 10(24):120-120.

[3] Yang Ning. Exploring and analyzing the college English education model based on intercultural communication ability training [J]. Journal of Suzhou Education Institute, 2014, 17(5): 145-146.

[4] Xiu Bo. Exploration of College English Teaching and Intercultural Communication Ability Cultivation [J]. Found, 2018, 13 (3): 103-104.

[5] Ma Jianping,Zhang Qishu.The Cultivation of College English Intercultural Communication Ability from the Perspective of Hermeneutics[J].Journal of Shandong Agricultural Engineering University,2015,32(2):126-127.

[6] Xiao Haiyan. Discussion on the Relationship between Intercultural Communication Ability Cultivation and College English Teaching [J]. Curriculum Education Research, 2017, 24(10): 33, 123.

[7] ZHAO Wei. Strategies for Cultivating Intercultural Communication Ability in College English Education [J].Heilongjiang Higher Education Research, 2016, 31(5):142-144.

[8] Chen Wei,Wang Xueli.Construction of English Intercultural Communication Teaching Mode from the Perspective of Constructivism_-Analysis of the Construction of English Intercultural Communication Course in Nanjing University of Posts and Telecommunications[J].Journal of Southwest Agricultural University(Social Science Edition),2013 , 11(6): 152-156.

[9] Wang Wei. The New Question Type of College English Translation for the Construction of Intercultural Translation Teaching Model [J]. Education and Teaching Forum, 2015, 19(1): 137-138. 